\title{
Observing the Atheist at Worship: Ways of Seeing the Secular Body
}

Lois Lee, University of Kent

In 2010 architects Tom Greenall and Jordan Hodgson were commissioned to design what became the 'Temple of Perspective' (de Botton 2013), re-christened 'the Atheist Temple' in media treatments. The client was British public philosopher Alain de Botton and, though the building was never built, an impression of the Atheist temple appears in de Botton's 2013 volume, Religion for Atheists. ${ }^{\text {ii }}$ The temple was in fact one of several buildings designed for this volume; the project also resulted in designs for a 'Temple to Love', a 'Shrine to the Mayfly', a 'Shrine to Care', amongst others. But it was the Atheist temple that featured most prominently in the volume and wider media discussions, including the British Guardian and Telegraph newspapers and Timeout magazine. In 2012, a model of the building was also presented at the British Royal Academy's flagship Summer Exhibition.

In this chapter, I explore how we can make sense of the imagined visitor to this imagined space to help understand the 'cultivation of the distinct sensibilities, affects, and embodied dispositions that undergird secular forms of appraisal and practice' (Hirschkind, 2011: 633). In so doing, the chapter responds to the provocation from anthropologist Charles Hirschkind that scholars address the question, 'what is a secular body?' and explore what our 'answers-or refusals to answer-tell us about the practical and conceptual contours of the secular and secularism' (ibid.). The provocation is a welcome one, since the meaning of the 'secular' has remained remarkably elusive (Lee 2015; Taylor 2007), even though the term itself has become familiar and widespread - possibly because many discussions are theoretical, speculative and/or engage with the 'secular' in very general terms. The problem we arrive at 
is summed up very concisely by Hirschkind (2011: 641) when he says, 'while the statement, "He [or she] lives a very religious life" gives us some sense of the shape of a life, "He [or she] lives a very secular life" tells us almost nothing (except, negatively, that the person does not engage in practices of worship)'.

In this chapter, I argue that Hirschkind's frustration arises, at least in part, from the limitations of the critical approach that Hirchskind uses to think about the secular. I propose an alternative, one that builds on productive tensions between critical secular studies and another approach, nonreligious studies, which has largely developed in parallel. Where critical scholars tend to work with secularity qua regime, framework or context, nonreligious studies scholars work with secularity qua the experience and outlooks of nonreligious individuals and populations. Bringing these approaches into conversations presents a helpful 'third' approach, one which accepts the view that phenomenal secularity (that which is designated 'secular' by actors, including academics) has distinctive qualities to it, but that these are more numerous and more complicated than the encompassing notion of secularism that critical scholars allows (Lee 2015; cf. Wohlrab-Sahr 2011; Wohlrab-Sahr \& Burchardt 2012; Burchardt et al. 2015).

In this approach, we can pull at that richly detailed tapestry that critical scholars call secularism to reveal the warp threads upon which it all relies, and thereby open our analyses to the many different tapestries that might be woven about them. To this end, the chapter explores the value of recognising some of these foundational 'threads' - what I refer to as the immanent-secular, secularism, nonreligion and non-traditional existentiality - as analytically autonomous from one another, so that we can imagine not only 'an immanent life', but also 'a secularist life', 'a nonreligious life', and 'an existential life' in ways that give a meaningful sense of those lives. As Monika Wohlrab-Sahr (2011) argues, critical studies of secularism have been enormously productive yet they hit a wall if they insist on working genealogically to the 
exclusion of all else. I hope to show that developing analytical concepts from that genealogical work will help us find new pathways forward, whilst also addressing major issues within the two dominant approaches to secularity: the tendencies in critical secular studies to generalise and in nonreligious studies to naturalise what it means to be 'secular'. I begin by setting out these two approaches.

\section{Two approaches to 'the secular'}

Over the past two decades, new approaches to and sometimes beyond 'the secular' have started to build momentum and take form. The most significant of these are critical secular studies and nonreligion studies. The heterogeneous body of work known as critical secular studies addresses Western modernist forms of secularism as a broad ideological, political or cultural framework and is associated with philosophical and anthropological scholars such as Talal Asad (2003), Webb Keane (2007), Saba Mahmood (2005), Charles Taylor (2007) and others. The burgeoning, equally diverse nonreligious studies engages much more with identity, experience and subjectivity of people identified (by themselves or by others) as irreligious or nonreligious, as well as with the cultures that manifest in activist organisations, new congregations like the Sunday Assembly and in everyday experiences and performances of difference from religious 'others' iii 'This work is most commonly undertaken by sociologists and psychologists, but also by anthropologists (who often work with nonreligious actors who participate in organised forms of nonreligion [see for example Luehrmann 2011, Aston, this volume, and Engelke, this volume]).

Though these two scholarships have often developed in parallel and have not engaged with each other as deeply as they might have (cf. Beckford 2012), iv they both shift attention 
from 'the secular' as a measure of religion's absence towards an idea of 'the secular' as describing a set of experiences and cultural formations, which are concrete and necessarily instantiated in material forms, including the human body. In identifying secularity as sociocultural experience, these scholarships both make and instantiate 'cultural turns' in the study of secularity (cf. Wohlrab-Sahr and Burchardt 2015). But, though they are animated by overlapping theoretical concerns and empirical foci, they also have significant differences that have allowed them to develop in relative isolation from one another: critical work focuses especially on how distinctions between religious and secular that in some way prioritise the secular are made - on secularism, that is - and on the power and influence that secularists and -isms exert (Lee 2012; 2015; Wohlrab-Sahr and Burchardt 2012); nonreligious studies focus much more on nonreligious populations, especially on individuals' experiences and subjectivities, as well as charting the characteristics of those populations.

Underlying these differences are other distinctions. Critical secular studies' 'cultural turn' is driven by a critique of the secularity and secularisms of Western governments and other authorities, and tends to the view, often implicit, that religious actors are more vulnerable to these powers than nonreligious ones are. Underlying much of this work is an emancipatory goal for religious people and traditions, by educating the 'secularist' out of the naïve notion of religion that they are perceived to hold innocently or wield strategically over the religious. This scholarship has led to a much richer understanding of how a particular and powerful secularist attitude has shaped and continues to shape the social world. On the other hand though, it has tended to make generalised remarks about what 'secular' actors say, think or do, while its empirical work has focused on religious actors in relation to broader secular frameworks or contexts (Lee 2015: 60; see also Hirschkind, 2011: 635). Consequently, its 'cultural turn' is incomplete in the sense that it has not yet fulfilled the potential of its own logic since it does 
not pay equal and sustained attention to the nonreligious actor as existing, impactful, and embodied, nor to the nature, heterogeneity and contingencies of nonreligiosity and the invested interests that structure it.

In the second strand of work, scholars have started to recognise nonreligiosity (often referred to as 'secularism' in north America, or as 'atheism' in a number of Protestant and post-Protestant contexts) $^{\mathrm{v}}$ as concrete and meaningful in the formation of subjectivities and societies. This second 'cultural turn' (of sorts) is much less concerned with distinctions between religious and nonreligious - frequently, in fact, pointing to similarities between them, such as a common capacity for moral thought and ethical practice. Rather, it seeks to recognise and understand a set of positions and experiences that are identified in contradistinction to 'religious' ones, that is, as nonreligious (Lee 2012; 2015; Quack 2014), and which have not been widely studied until recently (Lee and Bullivant 2012). Because this work responds to a disparity between the large number of nonreligious people and cultures on the one hand and the small number of detailed empirical treatments on the other, it is empirically focused. ${ }^{\text {vi }}$ If Talal Asad has produced the canonical works of the critical secular tradition, and social anthropology and political philosophy provide its disciplinary home, Colin Campbell's 1971 volume (reprinted in 2013), Towards a Sociology of Irreligion, is the touchstone for those working in this second area, and scholars from sociology, psychology are its main contributors.

By different means, this scholarship has produced its own picture of the 'secular' individual - describing them in terms of their demographic profile, their participation in social movements, and their health and wellbeing. However, this work has not always been sufficiently critical of the secularisation paradigm, so that the 'secular' individual is still often understood negatively, in terms of the religion they are without and the outcomes of this without-ness, rather than in terms of the new beliefs and cultural formations that these 
individuals participate in. The 'cultural turn' here is methodological rather than conceptual, recognising the 'secular' individual as a subject, yet not necessarily identifying secularity as a mode of subjectivity per se. A second issue is that, in addressing hostile accounts of the nonreligious person, this work is sometimes defensive, and therefore desensitised to ambivalences. Its real limitation, though, has been the relative lack of qualitative accounts of so-called secular populations, illustrating that, as with the critical secular studies project, the logic of this second cultural turn is in some sense unfulfilled.

When Webb Keane describes 'secularism' as 'a project, not a return to some natural condition from which humans deviated' (2008: 161) he provides a neat summary of the two visions of the secular that I have outlined above: one that is primarily critical of the secular as an ideological project, and another that takes nonreligious populations and outlooks seriously in its methodology but does so in order to better prove a naturalised, universalist account of the secular. In this chapter, I draw attention to the value of a third option - something between the naturalised idea of secularity as the condition of being unencumbered by religion as - of just being 'normal' - and the ideological notion of secularity as a project. It arises from looking in more detail at micro-level 'secularity' (as nonreligious studies do) but attending much more closely to the cultural contexts that shape bodily experience, habits and sensibilities (as critical secular studies scholars do). I argue that searching for secularity as cultural formation but doing so through close attention to the nonreligious subject leads to the need for a much broader armoury of concepts to describe the different layers to this 'secularity' and, ultimately, a move away from the idea that those layers configure in a single, coherent, stable and predictable cultural formation that we can call 'secular'.

\section{Many-layered 'secularity'}


Despite the wide-ranging work undertaken within the two broad and heterogeneous approaches identified above, there is potential to expand their understandings of the 'secular'. There is by now enough work around 'nonreligious subjectivities' (e.g. Mumford 2015; Lee 2015; Baker and Smith 2015) to show that the purely negative account of 'secularity' as being without religion is insufficient. On the other hand, though, the complex of attributes that critical secular studies identifies as secular is so very - perhaps unwieldingly - thick that it can be challenging to apply it to micro-level experience and practice. What I propose is that we identify and disentangle the threads that form the warp of the tapestry critical scholars present us with - that richly described, thickly historical, ideological secularism that elides with Western modernity, and its nation-state politics, rationalism and scientific epistemology. In so doing we can isolate finer-grained concepts that help us to describe and understand what it means to live 'a secular life' in more nuanced terms and, significantly, explore the multiplicity of ways in which it is possible to be secular. I want to set out four main ways of thinking about 'secularity' and understanding 'secular bodies', all of which arise from past fieldwork with English people who identify as 'not religious' or 'nonreligious' (Lee 2015).

First is 'secularity' as immanence in the Kantian sense - a way of describing the realities that manifest in the 'immanent frame' (Taylor 2007). This secularity involves an immersion in 'this-worldly' space and time that is contrasted with a capacity to transcend them both - to view this world from an 'other-worldly' plane, or to understand secular time in relation to eternity. This notion of secularity is close to the traditional, Christian one (Knott 2005; Taylor 2007), and in my work, I use the term 'secularity' solely to describe this particular 'warp thread'. I find it sufficiently specific and concrete to imagine what a 'very secular life' might entail: a life lived with a limited or dampened temporal awareness and imaginary capacity. Presuming 
that this kind of radical here-and-now-ness is quite rare, in practice this 'secularity' might be most evident in periods of life that are more secular than others, or particularly secular domains, moments or situations. Alternatively, we might think about secularity as a framework, as Taylor (2007) does, one that does not eradicate experience of transcendence but nevertheless curtails it in important ways. In opposition to Hirschkind's argument that the concept of the 'secular' offers nothing that other concepts (rationalism, liberalism, modernism) do not already describe, I hope to demonstrate that this idea of secularity as immanence helps us describe something distinctive.

Though scholars have repeatedly tried to trouble it, 'secularity' is most commonly located in a binary with religion. Secularity in the narrower, Christian sense is however more accurately contrasted with eternity, or conceptions of eternity brought about through transcendence. The eternal actually has a place within critical notions of secularity, as in the idea that secularity connotes a type of 'worldview' - a philosophy of life, existence and reality that is, commonly identified as materialist or humanist (e.g. Keane 2013: 159). I use the concept of 'existentiality' (or sometimes meta-existentiality) to describe the relationship that humans have with the eternal, since this relationship is also one with the nature and perimeters of our own existence. Historically, religious traditions have been central to the cultivation of existential experience, but the notion of existentiality I develop in my work (e.g. Lee 2015) is one of several recent attempts to also engage with 'philosophies of life' outside of traditional religious contexts (see Taves 2016). This emerging scholarship shows that 'secular' individuals have the capacity to imagine beyond their physical, secular existence and thereby conceptualise (in a very broad sense) that existence in ideas, symbols and practices (Baker and Smith 2015; Lee 2015; Mellor and Shilling 2010; Taves 2016). ${ }^{\text {vii }}$ This idea of non-traditional modes of existentiality is the second thread I want unweave from that tapestry of 'secularism', and then 
recast claims about it as hypotheses. The extent to which 'modern' modes of existentiality are materialist (Keane 2013), humanist (Taylor 2007) or postmodern and agnostic can be approached then as empirical questions, and open ones since a sociology or anthropology of existentiality or 'worldview' is just beginning.

Though the 'secular' and 'secularism' are often used interchangeably, I follow Asad (2003) and some others in insisting on the need to distinguish between them. The third key analytic concept that can be unwoven from critical notions of the secular is, then, secularism, understood narrowly as a theory, ideology or other system of constructing the secular, that is, of demarcating social and psychic domains in which immanent concerns have primacy and specifying the nature of that primacy (Lee 2015; 2016). Experience, ideas and cultures concerning the eternal and the existential may play a role in these domains, but secularity implies that this role is at least secondary to governing logics derived from immanent concerns (ibid.). In general terms, to live a secularist life would be to proceed through the world constantly engaging with - advocating, questioning, etc. - ideas about the relevance and legitimacy of the transcendent in particular domains: to be responsive to discussing transcendent existential topics with friends, for example, but resistant to, even shocked by, these themes being raised in a job interview setting; to visit a designated place of worship to kneel in prayer, but resist the idea of kneeling in prayer on a city street.

The benefits of thinking about secularism as a warp thread rather than a whole tapestry include the opportunity to explore diverse secularisms, including religious ones as well as nonreligious ones. This means that, instead of seeing secularism and nonreligion as intrinsically bound together, we need to disentangle them. This brings us to a fourth key concept of 'nonreligion', understood in relational terms to describe phenomena that are primarily identified in contradistinction to the religious (Lee 2012; 2015; Quack 2014). Embodied 
nonreligion might be irreligious, for example: in past fieldwork with nonreligious Britons I met people who were consciously training themselves to 'un-learn' or de-habituate what they saw as superstitious habits, such as throwing salt over the shoulder for good luck. Others talked about less conscious experiences of 'un-disciplining', such as feeling physically repelled by certain religious beliefs and practices - muscular resistance to bowing the head in prayer in the context of Christian worship, for example, or passionate, visceral anger experienced by the bereaved confronted by religious ways of memorialising the dead. As well as irreligious modes of nonreligion, though, others describe another kind of embodied nonreligion, in which they experience sensations of excitement and wonder in relation to religion that is charged by their sense of otherness from it - by their sense of religion as exotic, for example (e.g. Lee 2015: 34). Significantly, this nonreligiosity sometimes has to do with the immanent world (having to do with mundane matters of clerical corruption, for example), but not always: the anger felt by the person mourning in a non-Christian way is non-secular when it is driven by an alternative idea about the nature of eternity; the sense of religion as exotic can arise from a sense of having differing beliefs about the nature of existence. Again, this is the kind of nuance that conflating nonreligion, secularism and secularity can obscure.

All of these concepts - the immanent-secular, the secularist, the nonreligious and the existential - offer, then, distinctive approaches to thinking about ways of living and about the body that are not encompassed by concepts like modernism, rationalism or liberalism. To imagine the possibilities of this approach, I now turn to another work of imagination: a vision of an 'atheist temple' and of the 'atheist worshipper' who might occupy it.

\section{The Atheist at worship}


Courtney Bender has recently proposed that sociologists and anthropologists interested in the everyday realities of religiosity engage more closely with the way in which public, governmental and elite actors 'not only imagine, but experience' what she describes as 'post-religious' modes of religion, spirituality and secularity (2016b: 102; 104; 107). In this work Bender explores another unrealised architectural project: Frank Lloyd Wright's plans for Broadacre city in the US. Bender's analysis is primarily spatial, and I have likewise taken a spatial approach in consideration of the Atheist temple elsewhere (Lee 2017). But space and the body are inseparable (Knott 2005; Vasquez and Knott 2014, in Lee 2017) and here I turn attention to how the spatial shapes and is shaped by 'body pedagogics' (Mellor and Shilling 2010), in processes which might cultivate distinctive modes of 'sensibilities, affects, and embodied dispositions' (Hirschkind 2011).

\section{Image 1: The Temple to Perspective}

The imagined Atheist temple is a skyscraper, with an internal space comprised of a single, dramatically elongated atrium. In a beautiful image of the building (see Image 1) produced by the architects and circulated in the media, the building is imagined in the heart of the City of London, surrounded by the distinctive skyscrapers of London's financial district. Another image shows a cross-section of the building (see Image 2), in which we see a single figure: a man, standing alone, dwarfed by the cavernous space that rises towards an open view of the sky and from which a dramatic shaft of light descends. In exploring multilayered ways of thinking about the 'secular body', the following section considers the ways in which existentiality, the secular-immanent, secularism and nonreligion are manifest in the building itself and the imagined bodies that occupy it. 
Image 2: The Atheist Temple

\section{The Atheist worshipper and the existential body}

The mode of existentiality that the Atheist temple is designed to cultivate as bodily sensation closely conforms with the existential humanism that critical secular scholars often anticipate as part of a 'secular' cultural complex. viii The building's architects reference humanistic tenets explicitly in describing the building's form. In the architects words, 'the entire history of life on Earth' is depicted on the walls of the 46-meter high space, with '[e]ach centimeter of its height equate[d] to one million years of life'; and, at its base, a single band of gold - 'one meter from the ground and no more than a millimeter thick' - represents the existence of humankind. ${ }^{\text {ix }}$ The outside of temple is also inscribed with 'an interpretation of the human genome sequence,' which the architect says is 'a celebration of one of humankind's greatest achievements, while simultaneously a reminder of our fragility'. It is by these means, they intend that a visitor to the temple should leave 'with a renewed sense of perspective' (ibid.). These ideas and representations reference a materialist conception of existence, but it is also explicitly human-centred - in its valorization of human capacities and achievements in human knowledge (the genome sequence); in its foregrounding of humanity over other animals (the gold band); and in its adoption of a 'human gaze' which the temple's titular sense of 'perspective' is relative too. Humanity's existence is the temporal standard against which existence of material reality is measured and conceptualized; the latter is not represented as relative to the history of life in general on earth say, nor to the history of primates or any other life form, nor to the history of earth itself; nor is it relative to the human lifespan, nor the 
lifespan of a particularly feted individual. Rather - and archetypically for existential humanism - perspective is scaled to the history of humanity as a species.

The architects clearly intend that visitors to the Atheist temple engage intellectually with these representations, and frame their life in humanist perspective. But this humanism is also cultivated as a bodily experience, since the form of the space and the body's relation to it encourage the occupant of that space to experience it through particular bodily sensations also associated with humanist traditions. The space encourages the imagined visitor to take on the role of worshipper by experiencing their body as small - 'fragile', as the architects put it - and by responding to the story of existence told on its walls through bodily practices of quietude, reverence, awe and wonder, since the long, narrow atrium space would not only dwarfs the visitor but encourage their eye upward, following the visual lines of the tapering walls to the apex and drawn to light that only enters the space there. The intention is that the building will effect exert its force on the body of the visitor, so that they experience themselves as smaller, less significant and more alone than they did in the streets outside; 'perspective' is in this way something that is wrought upon the body.

The building is also designed to isolate the individual body, so that the visitor's experience is focused entirely on their intellectual and physical relation to a set of existential ideas. In her discussion of Evangelical Christian body pedagogics, Anna Strhan (2015: 68-69) develops Michel Foucault's ideas about moral reflexivity as an embodiment of Christian subjectivity and Jeremy Carrette's focus on silence as an aspect of this subjectivity. She shows how the British Evangelicals she works with 'seek to disciple(in)e themselves and each other through different kinds of silence' (ibid: 69). A similar bodily repertoire is referenced in the Atheist temple, in which 'worshippers' are encouraged to respond through awe, reverie, interiority and quietude - though it is also striking that the Atheist temple perhaps invites 
visitors to experience the space and the existential in solitude, rather than as part of a communal silence.

These embodiments of humanist existentiality can be understood in relation to wider existential experience in the UK. For one, the architects necessarily draw on the existential cultural conventions in the context in which they live and work, since they intend that people will be able to make sense of the space when they visit it, the more so because the Atheist temple project had a 'missionising' objective to convince people that existential practice and the spaces that facilitate them are needed in contemporary societies (De Botton 2013). The design therefore reflects modes of existential thought and practice that are more widely cultivated though bodily as well as intellectual 'disciplining'. Consider, for example, a practice that Rachael Shillitoe (2017) observes in fieldwork exploring religion and nonreligion in British primary schools: Shillitoe describes how one school she worked with responded to the legal requirement to practice daily collective worship by reading a poem encouraging the children to reflect on things they were grateful for. These assemblies cultivate an embodied practice of gratitude, imparted by an authority figure to a group, consumed collectively and in silence, and construing gratitude as something that is manifested through self-reflection (rather than through expressive action, say). William Connolly writes about 'little moments' of 'gratitude in existence' (2011: 651, my emphasis), and my research documents how individuals can experience such moments as sparked by an immediate object (a reason to be grateful), or as if out of nowhere (e.g. Lee 2015: 179). Yet Shillitoe's work demonstrates how registering gratitude and experiencing it in certain ways is cultivated through practice. Through such practices, people learn to recognise some phenomena (and not others) as existentially significant, and to notice them as existential under particular conditions - in quiet spaces, for example. 
The Atheist temple also references specifically humanist traditions of cultivated bodily sensation. There is, for example, a tradition of exploring humanist existentiality through sensations of awe. This might be cultivated through viewing what media historian Alexander Hall (2017) calls 'humanist blockbusters' - the expensive BBC science and nature programming of the twentieth and twenty-first century that uses emotive language, sweeping scores and richly cinematic cinematography to inculcate an intensely emotional experience of wonder in response to humanist narratives of existence.

This form of existential humanist sensibility is particular, and can be differentiated from other forms of humanist sensibility. An instruction comparison can be made here to another work of architectural imagination, Frank Lloyd Wright's vision for Broadacre city, which Bender explores in her work (Bender 2016a; 2016b). Of particular interest is Lloyd Wright's design for an 'automobile objective', which involved a planetarium, restaurant and scenic, high-up viewing point over the suburban vista. Like the Temple to Perspective, proposals for the automobile objective were also unrealised; and, like the Temple to Perspective, the architectural vision was explicitly concerned with creating existential experience - which Bender describes somewhat ambiguously as 'post-religious religion' (Bender 2016b), and which is popularly termed 'spirituality' in the US and sometimes also in the UK context. The mode of existentiality that Bender identifies is recognisably humanist: she shows how it celebrates human achievement, especially technology, is founded on a sense of human progress, and that there is an explicit attempt to cultivate these ideas in how people physically use and experience the building.

Beyond those significant similarities, though, there are also striking differences between the two humanisms. Greenall and Hodgson's temple is imagined in the heart of the city of London; Lloyd Wright's automobile objective is imagined within a mid-century 
American suburban context. Whilst the Atheist temple encourages the visitor into a position of stillness, the visitor to Broadacre's automobile objective is mobile, moving up and around the edifice of the building by motorcar; in this building the individual does not look up to the apex, they come to occupy it, and look down upon and across the vista before them. In Bender's subtle analyses, she uses the concept of the 'technological sublime' to explore how Lloyd Wright's vision recalls romantic nineteenth century images of the white man - as it was, and is also in Lloyd Wright and Greenall and Hodgson's imaginations - gazing down upon the world, awestruck partly by its mystery, partly by his feeling of confident mastery over it. The human visitor is invited to be impressed by the world out there, as they are in the Atheist temple; but in Broadacre they are not encouraged to feel this through a sense of their vulnerability or fragility, but their strength and authority.

There is not space here to unpack the differences between these existential humanist imaginaries in detail, but this sketch indicates the heterogeneity of humanist existentialities, shaped by their locations in geo-cultural contexts and capable of leading to distinctive modes of bodily experience - through the relationship of the body to its environment (below-ness versus above-ness; stillness versus movement), through emotional repertoires (awe, reverie, humility; awe, facility, authority), and through practices of sociality (idealisation of isolation and solitariness; idealisation of participation and movement in small, probably domestic units). Instead of generalising about 'secular worldviews', then, these kinds of analyses can show how 'secular' existential projects have 'shaped, articulated, broadcast, and provided space for [people] to experience their "spiritual" selves' (2016b: 106) in distinctive ways.

\section{The Atheist worshipper and the nonreligious body}


For Hirschkind, the one thing that the concept of secularity might tell us about a person is the 'negative' information 'that the person does not engage in practices of worship'. For Hirschkind this is meagre knowledge, yet recent years have seen the development of relational studies of different kinds of 'negative' positioning as a major strand in nonreligion studies, associated with my own conceptual work around 'nonreligion' (e.g. Lee 2012; 2015) and typified by Johannes Quack's anthropological field theoretical approach (Quack 2014).

In the Atheist temple, nonreligious relationality is manifest in at least two different ways. Firstly, nonreligiosity is visible in the identity that the building manifests - taken on by the visitor incidentally, by participating in a space itself identified through nonreligious categories. ${ }^{x i}$ Nonreligious identities are commonplace in places like the UK, especially since they are sometimes carriers of existential meaning, particularly in 'detraditionalised' contexts like the UK where new existential orientations are rarely consolidated and codified in centralised institutions; that is, in the absence of 'positive' ways of identifying their existential beliefs and worldviews, individuals turn to the nonreligious concepts that are available to them (Baker and Smith 2015; Lee 2015; Mumford 2015). Nonreligious identities are not always carriers of existential meaning though, and may have other kinds of significance. As significant identities, they are also the main point at which we can see the 'secular' as a manifestation of socio-cultural positionality - as habitus, in Bourdieuisian terms (see also Gutkowski 2012).

In past work, I have discussed a passage taken from a piece in the London Review of Books, a well-known British literary magazine, in which the author describes '[m]iddle-class white atheists like me [who] sail around on our bikes to buy our coffee beans in Broadway Market or Victoria Park Village', the latter being fashionable, increasingly middle-class areas in the East End of London (Meek 2011: n.p.). One thing the passage illustrates is how nonreligiosity intersects with other aspects of identity such as socio-economic status, ethnicity 
and gender (as we learn from the gendered identification of religious others elsewhere in the piece), as well as the way in which all of these identifications are embodied. In the LRB example, the author's nonreligious identity is manifest in the occupation of a certain body (White, male) and certain spaces (Broadway Market), in physical practices (cycling in particular; mobility in general), and in cosmopolitan patterns of consumption (expensive coffee; travel). The imagined visitor to the Atheist temple (see Image 2) echoes Meek's portrait: the image shows a white man, apparently middle-class since he wears the accouterments of professional employment. A second picture produced by the architects also depicts a white man, this time in more casual attire but occupying a similar socio-cultural space. Both men are pictured in a building that itself is the creation of men in middle class occupations, and echo the profile of public Atheists in the UK as elite, white and male, from de Botton to Richard Dawkins (Bullivant 2010; Sheard 2014). The building itself is located within the City of London, one of the most affluent regions of the city and the world (Lee 2017).

We would be wrong to take this representation of the Atheist body at face value: although Atheists are likely to be white in the UK, they are commonly female and as likely to have lower socio-economic status as not. It is significant, though, that the idealized nonreligious body takes this form. Imagined bodies shape real bodies, through psycho-social processes of socialisation as well as the reproduction of power relations that influence imagined bodies and real bodies alike. Bullivant (2010) contrasts the white male figureheads of British public Atheism with the 'wild' female figurehead of US Atheism in the person of Madalyn Murray O'Hair, whose certainly strange story (involving kidnapping and murder) has recently been adapted into a Netflix film. These different bodies are significant, not only because they influence the way in which nonreligious actors are positioned in social contexts, as Bullivant shows, but because they are produced by those contexts - are manifestations of them. The 
Atheist temple draws attention to the way in which the bodies of the nonreligious 'laity' and representations of those bodies work alongside leaders' bodies and their representations to shape how nonreligious bodies are imagined and produced.

The body imagined in the Atheist temple is also meaningfully nonreligious in a quite different sense, through the relationship of otherness established in its vision of the Atheist at worship. As we have seen, the body is encouraged to experience its existentiality through a particular emotional repertoire and practices of comporting the body. These draw extensively from Christian, especially Protestant modes of understanding and being existential, which are historically significant in the UK and bound up with dominant discourses about religion and Britishness. Indeed, British nonreligion often references these traditions, for example in describing nonreligiosity through God- and belief-focused concepts (e.g. 'atheism', 'nonbeliever', 'unbelief') that also derive from these traditions. These religious traditions are also visible in the imagined Atheist temple - in cultivating the sense of existentiality as best experienced in private and quietness, and encouraging internal reflection and experiences of humility and awe in relation to the transcendent (Strhan 2015: 68-69; cf. Schmidt 2000). Though the transcendent force is human knowledge rather than God, these other Christian modes are largely intact. Moreover, the space itself references the familiar conical spires of Anglican and other church buildings in the UK, so that the relation of the imagined body to that space also replicates Christian modes of embodiment.

Many scholars have traced these kinds of cultural ties between Christianity and 'secular modernity'. However, the objective is often to challenge the idea that modernity involves a complete break from religious pasts, and this work tends to emphasise cultural contintuities the way in which 'secularity' is, in important ways, really religious. By contrast, relational approaches to nonreligion suggest that the way in which new cultural formations are 
differentiated from traditional forms is significant, that the production and reproduction of nonreligiosity is a process of cultural transformation. Scholars working more closely with irreligion and other forms of nonreligion have come to recognize that nonreligion always manifests something of the religion it is othered from (Campbell 2013 [1971]; Davie 2013), yet it would be wrong to say that nonreligion simply reproduces religion. Rather, processes of othering bring something new into being.

In the Atheist temple, a humanist existentiality draws on religious, especially Protestant traditions, and demonstrates an unbroken 'chain of memory' (Hervieu-Leger 2000). But it also a nonreligious space, which echoes Protestant traditions in order to challenge and overthrow them. One of Alain de Botton's broad objectives is to reshape the public sphere according to his own vision of he public good - something seen elsewhere in his work, such as his Living Architecture initiative, which aims to expand the role of contemporary architecture in popular culture. His Atheist temple is one attempt to shape contested public space that the Church of England has dominated. At the same time, de Botton's project is situated in opposition to more radically anti-religious forces, which would like to see spaces (and other resources) dominated by religions eradicated rather than shared with non-traditional existential cultures.

Visitors to the Atheist temple would be implicated in these forms of nonreligious distinction-making. Some nonreligious actors would refuse to participate: the many people who experience their nonreligiosity as a physical recoil from practices that reproduce the bodily pedagogics of the religion(s) they reject might feel uncomfortable in the temple. Those who try to 'un-discipline' or 're-discipline' their bodies as part of a process of 'nonreligionisation' (Lee 2014) or 'atheisation' (Sheard 2014) might actively reject the project, as the prominent anti-theist public figure, Richard Dawkins, has done, seeing the notion of an Atheist temple as 'a contradiction in terms,' (Timeout 2012, n.p.). ${ }^{\text {xii }}$ These kinds of reactions 
also demonstrates how the Temple to Perspective allows visitors to be nonreligious in certain ways but not others: it explores and creates post-Protestant experience, but does not offer the same kind of opportunity for those who experience themselves as other to other religious traditions. In these different ways, the Atheist temple might affirm experiences of (certain forms of) nonreligious otherness, whilst also allow people to experience religious practice in new ways and inscribe it with new kinds of meaning in relation to non-traditional existential cultures.

\section{The Atheist worshipper and the secularist body}

We can also understand the visitor to the Atheist temple in terms 'secularism': practices of differentiation-making between the immanent or 'this-worldly' and the transcendent existential or 'other-worldly', and the prioritisation of the former in certain domains or in general.

Most significantly, the Atheist temple creates a space for the body to experience the existential and eternal as set apart from the non-existential and secular. Rather than engaging with this-worldly life, the building creates a forum in which the visitor solely engages with existential conceptualisations. The purity of this existential function contrasts with the role of the existential and the secular in comparable religious spaces. In fact, a 'practical turn' in the study of religion has called attention to the integration and significance of secular practice in religious life. Be it cooking in mosque kitchens (Kuppinger 2017) or the cleaning Church buildings (Day 2017), the status of such activities as secular or existential is often blurred. Yet in the Atheist temple there is no kitchen, no offices, no cleaning cupboards (Lee 2017: 139). Its sole purpose is for existential reflection, so that it not only cultivates reflection as a mode 
of existentiality but also cultivates an embodied understanding of a distinction between spaces in which existentiality is in general more (or less) relevant, more (or less) legitimate.

By helpful contrast, Lloyd Wright's automobile objective has several secular functions intermingled with its existential ones. Not only do the automobile objective and the Atheist temple express alternative humanist existentialities but also different forms of secularism.

\section{Is there a 'secular worshipper'?}

If we acknowledge that atheists can engage with alternative philosophies of life, which are experienced through practice as well as through thought, the idea of an Atheist temple and an Atheist worshipper is not contradictory in the way that, for example, Richard Dawkins imagines. By contrast, if we resist the critical secular scholar's tendency to collapse several meanings into the concept of 'secularity' and instead salvage the traditional, Christian sense of the term - as one in which transcendent existential concerns become in some way secondary to this-worldly, immanent concerns - the idea of the 'secular worshipper' is problematic. Strictly speaking, the secular cannot be worshipped and still be secular, since to worship the secular is to reflect upon it and thereby transcend it. But thinking in terms of a secular sensibility more generally, the Atheist temple if anything attempts to exclude secular life and sensibility, as we have seen, rather than cultivate it. In this temple, the imagined 'worshipper' is called away from and out of secular time and the concerns of immanent life; they are fully immersed in transcendent existentiality, not only metaphorically but viscerally, since the visitor's body is at once absorbed into the cocooning form of the atrium and raised above it, carried up and into the unseen world beyond the window at the apex. 
The non-secular nature of the Atheist temple relies on distinctions between immanent and transcendent, secular and existential, and this may make the secular relevant to bodily experience within the temple. If the 'atheist worshipper' focuses on the existential within the temple, this focus is partly achieved by distinction from the secular bodies moving about outside of it. The physical stillness that the temple seems to encourage likewise contrasts with the mobile and mundane bodies in the city streets beyond. Georg Simmel sees entranceways as intrinsic to processes of human sense-making, 'through a capacity to connect and separate things' (discussed in Strhan 2015: 29-31). ${ }^{\text {xii }}$ In this way, the Atheist temple attempts to divest visitors of their secular sensibilities at the door, yet would derive some its affective power from the visitor's transition - though partial and imperfect - from existential to secular as they enter (or leave) the space. Though the Atheist temple would perhaps not cultivate a secular body, it might then cultivate a de-secularising of the body as part of its attitude towards what it means to engage in existential thought and practice. If Greenall and Hodgson's temple would not cultivate secular sensibilities within its confines, therefore, it might inform secular sensibilities outside of it, whilst also cultivating a form of existential secularism that strictly separates and delimits the existential within the world.

\section{Conclusion}

Charles Hirschkind's skepticism about the concept of the 'secular' demonstrates, quite rightly, that our enquiries need to be brought down to earth if we are to know whether and how the concept has any real analytic force. In this chapter I have argued that new methods of disentangling the concept of the secular into a series of narrower, more specific and more concrete analytic categories is one useful outcome emerging from the empirical study of the 
nonreligious person in nonreligious studies, and that these concepts stand to help us to get a better handle on the phenomena that critical scholars are also interested to account for. In exploring the Atheist temple, these concepts - immanent secularity, ideological secularism, relational nonreligiosity and nontheistic but still transcendent existentiality - all help us to imagine and think about different modes of embodiment that might emerge therein.

Distinguishing these separate 'threads' also helps to address issues within both critical secular studies and nonreligion studies. Building on both bodies of work, the multidimensional and multifaceted approach I advocate tries to cut across their tendencies to focus on 'secular' contexts and on 'secular' individuals (but not secular subjectivity) respectively. This is an affirmation of Hirschkind's method of investigating the cultural waters that we swim in by exploring the movements, contortions and sensations of the swimmer. If I also end up agreeing with Hirschkind that we should indeed be sceptical of existing notions of the 'secular', this is not however because I also find it difficult to imagine distinctively secular lives and bodies (as he does), but rather because I find it difficult to imagine a single coherent way in which this might be so. In theory, my approach argues that what we have meant by 'the secular' in fact captures several discrete characteristics, all of which are not captured by other concepts. But in practice, too, these categories help us respond to an emerging emphasis in scholarship on the historical multiplicity of 'secularities' (Wohlrab-Sahr \& Burchardt 2012; Burchardt et al. 2015), which in turn calls into question that idea of one dominating secular or secularist formation through which we can understand vast socio-cultural domains over extensive periods of time. In fact, one lesson of critical scholarship might be precisely that we would be wise to question the conceptual framework bestowed on us by ideologies invoking the secular - that recognizing them as ideologies (as critical secular studies allow us to) should invite us to reconsider whether those ideologies should set the terms of the discussion. 
This chapter presents only a tentative exploration of how conceptually disentangling layers of 'secularity' might impact understandings of the body, and its limitations include a focus on the imagined body, rather than an ethnographic account of real bodies in action. Even in conceiving of the 'secular body' in new ways is, however, a leap of imagination that may open up new opportunities for identifying and understanding the nature of 'secularity' as embodied in future empirical projects. The separate ways of describing the 'secularity' of the body set out here allow us to consider, for example, the way in which these layers of secularity can be tangled together, as well as the possibility that they are not always so. It is this last possibility that indicates that the single category of the secular, which has, over recent years, carried us on a long and enriching journey, may at some point prove a roadblock to our attempts to deepen our enquiries and understanding.

\section{References}

Asad, T. (2003), Formations of the Secular: Christianity, Islam, Modernity, Stanford, CA: Stanford University Press.

Baker, J. O. and B. G. Smith (2016), American Secularism: Cultural Contours of Nonreligious Belief Systems, New York, NY: New York University Press.

Beckford, J. A. (2012), 'SSSR Presidential Addressișpipipublic Religions and the Post-secular: Critical Reflections,' Journal for the Scientific Study of Religion 51, 1 (2012): 1-19.

Bender, C. (2016a), 'How and Why to Study Up: Frank Lloyd Wright's Broadacre City and the Study of Lived Religion,' Nordic Journal of Religion and Society, 29: 100-116.

Bender, C. (2016b), 'Rethinking the 'Technological Sublime’: Wright's Urban Planning and Secular Uses of Religion,' Scientific Study of Nonreligious Belief Lecture Series, UCL (University College London), 26 July 2016. 
Bullivant, S. (2010), 'The New Atheism and Sociology: Why Here? Why Now? What Next?' in A. Amarasingam (ed.). Religion and the New Atheism: A Critical Appraisal, 109-24, Leiden: Brill.

Bullivant, S. and L. Lee (2012), 'Introduction: Interdisciplinary Studies of Non-religion and Secularity: The State of the Union,' Journal of Contemporary Religion 27 (1): 19-27.

Burchardt, M., M. Wohlrab-Sahr and M. Middell (2015), 'Multiple Secularities Beyond the West: An Introduction,' Multiple Secularities Beyond the West, Marian Burchardt, Monika Wohlrab-Sahr and Matthias Middell (eds), Berlin and Boston: De Gruyter.

Campbell, C. (2013 [1971]), Towards a Sociology of Irreligion. No place: Alcuin Academics.

Connolly, W. E. (2011), 'Some Thesis on Secularism', Cultural Anthropology 26 (4): 648-56. DOI: $10.1111 /$ j.1548-1360.2011.01117.x.

Cragun, R. T., L. L. Fazzino and C. Manning (eds) (2017), Organized Secularism in the United States: New Directions in Research, Berlin and Boston: De Gruyter.

Davie, G. (2013), 'Belief and Unbelief: Two sides of a Coin,' Ecclesiastical Law Journal, 15, 259266.

Day, A. (2017), The Religious Lives of Older Laywomen: The Last Active Anglican Generation, Oxford: OUP.

de Botton, A. (2013), Religion for Atheists: A Non-Believer's Guide to the Uses of Religion, London: Penguin.

Gray, J. (2012), 'Alain de Botton's atheist temple is a nice idea, but a defunct one,' The Guardian, 2 Feb 2012. Available at https://www.theguardian.com/commentisfree/2012/feb/02/alain-de-bottonatheist-temple-defunct, accessed 4 Sept 2017. 
Gutkowski, S. (2012), 'The British Secular habitus and the War on Terror', Journal of Contemporary Religion, 27 (1): 87-103.

Hall, A. (2017), 'Evolution on the small-screen: Reflections on media, science and religion in twentieth-century Britain,' conference presentation at Science and Religion: Exploring the Spectrum, June 2017.

Hervieu-Leger, D. (2000), Religion as a Chain of Memory, New Brunswick, N.J. Rutgers University Press.

Hirschkind, C. (2011), 'Is There a Secular Body?' Cultural Anthropology 26 (4): 633-47. DOI: 10.1111/j.1548-1360.2011.01116.x.

Keane, W. (2007), Christian Moderns: Freedom and Fetish in the Mission Encounter, Berkeley: University of California Press.

Keane, W. (2013), 'Secularism as a Moral Narrative of Modernity,' Transit: Europäische Revue 43: 159-170.

Knott, K. (2005), The Location of Religion: A Spatial Analysis, London: Equinox.

Kuppinger, P. (2017), 'At Home in the Multicultural City: Islam and Religious Place-making in Stuttgart, Germany ', in D. Garbin and A. Strhan (eds), Religion and the Global City, London: Bloomsbury.

Lee, L. (2012), 'Talking About a Revolution: Terminology for the New Field of Nonreligion Studies,' Journal of Contemporary Religion, 27 (1): 129-139.

Lee, L. (2014), 'Secular or Nonreligious? Investigating and Interpreting Generic 'Not Religious' Categories and Populations', Religion $44 \quad$ (3): 466-482, doi.org/10.1080/0048721X.2014.904035. 
Lee, L. (2015), Recognizing the Non-religious: Reimaging the Secular, Oxford: Oxford University Press.

Lee, L. (2016), 'Nonreligion,' The Oxford Handbook of the Study of Religion, M. Strausberg and S. Engler (eds), 84-94, Oxford: OUP.

Luehrmann, S. (2011), Secularism Soviet Style: Teaching Atheism and Religion in a Volga Republic, Bloomington: Indiana University Press.

Luehrmann, S. (2015) 'Was Soviet Society Really Secular? Undoing Equations between Communism and Religion,' Atheist Secularism and its Discontents: A Comparative Study of Religion and Communism in Eurasia, T. T. T Ngo and J. B. Quijada (eds), 134-154, Basingstoke: Palgrave Macmillan.

Mahmood, S. (2005), Politics of Piety: The Islamic Revival and the Feminist Subject, Princeton, NJ: Princeton University Press.

Meek, J. (2011), 'In Broadway Market,' London Review of Books, 9 August 2011. Available at <http://www.lrb.co.uk/blog/2011/08/09/jamesmeek/in-broadway-market/>, accessed 9 August 2011.

Mellor, P. A. and C. Shilling (2010), 'Body Pedagogics and the Religious Habitus: A New Direction for the Sociological Study of Religion,' Religion, 40: 27-38.

Mumford, L. (2015), 'Living Non-Religious Identity in London, Atheist Identities: Spaces and Social Contexts', L.G. Beaman and S. Tomlins (eds), 153—170, New York: Springer. Quack, J. (2014), 'Outline of a Relational Approach to 'Nonreligion',' Method and Theory in the Study of Religion, 26 (4-5): 439-69.

Schmidt, L. E. (2000) Hearing Things: Religion, Illusion and the American Enlightenment, Cambridge, MA: Harvard University Press. 
Sheard, M. (2014), 'Ninety-eight Atheists: Atheism among the Non-elite in Twentieth Century Britain', Secularism and Nonreligion, 3 (6): 1-16, Doi: http://dx.doi.org/10.5334/snr.ar.

Shillitoe, R. (2017), “Why are we Talking about Religion?” Reimagining Non-religion in Collective Worship,' Conference paper, British Sociological Association Sociology of Religion Study Group Annual Conference, 12-14 July 2017.

Strhan, A. (2015) Aliens and Strangers: The Struggle for Coherence in the Everyday Lives of Evangelicals, Oxford: Oxford University Press.

Taylor, C. (2007), A Secular Age. Cambridge, MA: Belknap Press of Harvard University Press. Vásquez , M. A. and K. Knott (2014), 'Three Dimensions of Religious Place Making in Diaspora', Global Networks, 14 (3): 326-47.

Wohlrab-Sahr, M. (2011), 'Multiple secularities and their normativity as an empirical subject,' Immanent Frame, 13 Dec 2011. Available at https:/ / tif.ssrc.org/2011/12/13/multiple-secularities-and-their-normativity-as-anempirical-subject/, accessed 4 September 2017.

Wohlrab-Sahr, M. and M. Burchardt. (2012), 'Multiple Secularities: Toward a Cultural Sociology of Secular Modernities,' Comparative Sociology 11 (6): 875-909.

27; 19: 46

\footnotetext{
i I have greatly appreciated the opportunity to develop this work as part of the 'Secular Bodies, Affects and Emotions' workshop held in Tübingen in 2016. Thank you to Monique Scheer, Birgitte Schepelern Johansen and Nadia Fadil for including me in this event, and to participants for their helpful comments on earlier versions of this chapter. Particular thanks to Birgitte Schepelern Johanse for her detailed, insightful and stimulating comments. The chapter was also made possible through the support of grants from the John Templeton Foundation (grant numbers 59544 and 60624); the opinions expressed in this publication are those of the author and do not necessarily reflect the views of the John Templeton Foundation.

ii De Botton is also known as the founder of the School of Life (SoL), an organisation that is frequently identified alongside the Sunday Assembly and New Atheism as a key example of organised nonreligion (or, in the US, 'organised secularism' [Cragun, et al. 2017]). The SoL uses religious language and formats such as
} 
Sunday sermons to provide metaphysical, existential and psychological guidance (at a price), via its six sites around the world and a successful series of YouTube lectures with approaching 3 million $(2,763,363)$ regular subscribers as well as other viewers at the time of writing.

(https://www.youtube.com/user/schooloflifechannel , accessed 1 Sept 2017).

iii See Bullivant and Lee 2012 and Lee 2016 for overviews.

iv As well as my own work (e.g. Lee 2015), Wohrlab-Sahr and Burchardt (2012) and Burchardt et al. (2015) are significant exceptions.

v I do not observe these conventions for reasons set out in Lee 2015 (also Lee 2012; 2014). In short, applied in this way both concepts are best seen as emic terms arising from particular Western traditions, despite being frequently taken up by (Western) academics as etic, analytic terms.

vi This work is of course motivated by many other factors too. These include, for example, the emancipatory agendas of nonreligious scholars working in contexts where nonreligion is marginalised; the growth, sometimes rapid, of nonreligious populations and nonreligious cultures in several parts of the world; and egalitarian concerns about the many differential ways that traditionally religious, alternatively spiritual, nonreligious and areligious actors are often understood by political regimes and in everyday social settings.

vii Cf. Luehrmann's (2015: 141-151) approach to transcendence (after Luckmann), which sees religious and nonreligious transcendence as distinct, echoing distinctions between 'horizontal' and 'vertical' transcendence in contemporary psychology of religion and nonreligion.

viii Existential humanism involves humanity-centred understandings of reality and human life, and can be differentiated from ethical humanism, which sees the flourishing of humanity and individuals qua humans as a good. Ethical humanism is not only compatible with existential humanism but with diverse existential orientations, including theistic ones.

ix http://www.tomgreenall.co.uk/project.php?sel=7, accessed 4 September 2017

x Johannes Quack's major collaborative project on the Diversity of Nonreligion is a major example. See Lee 2016 for an overview.

xi In the British context (as in many others), 'atheism' is usually seen as nonreligious, since theism is viewed as integral to religion (Lee 2015).

xii As well as Dawkins, other examples of those contesting the premise of the Atheist temple were fellow public Atheist, John Gray (2012), and a blog piece which included it in a list of 'construction projects we're kind of glad were never built' (http://www.citymetric.com/skylines/ 6-terrible-construction-projects-were-kind-gladwere-never-built-654, accessed 4 Sept 2017).

xiii See also Luehrmann (2015: 145) on the 'small transcendence' that building walls are able to create, and which are harnessed in religious ritual practice. 